\title{
The Perception of Muslim Female Athletes towards Formal Dress at Sand Volleyball Events
}

\author{
Akhmad Saufi* \\ Magister Management \\ University of Mataram \\ Mataram, Indonesia \\ akh.saufi72@gmail.com
}

\author{
Yulia Prayanti \\ Magister Management \\ University of Mataram \\ Mataram, Indonesia \\ yuliaprayanti123@gmail.com
}

\author{
S Sulhaini \\ Magister Management \\ University of Mataram \\ Mataram, Indonesia \\ niniys@yahoo.co.uk
}

\begin{abstract}
Sand volleyball can be promoted as sports tourism in Indonesia. However, the dress code of sand volleyball players is challenging for female Muslim athletes. This study aims to analyze the perceptions of female Muslim sand volleyball athletes toward the dress code at formal sand volleyball events. The research adopted qualitative methods. 40 female Muslim athletes of sand volleyball were recruited through purposive and snowball sampling. Data were collected by using an online interview technique. Data were recorded, transcribed, and then analyzed using content analysis. Results show three different orientations of the athletes' perceptions: (1) authenticity and professionalism perceive the dress code is unique to sand volleyball, comfortable, and help make flexibility in motion. The athlete should obey the dress code to show their integrity and professionalism; (2) compromise and achievement perceive that the athletes should focus on achievement. Sport regulation should help create confidence for the athlete. The athletes should gain the privilege to choose their dress based on their values and support from their communities; and, (3) religious and cultural values perceive that the dress code should be contextualized. The dress code should be based on the athletes' religious and cultural values as a form of equality in culture. The findings bring theoretical implications and suggest several managerial implications including the need to issue a dress code for sand volleyball athletes which is contextual to Indonesia, in order to increase participation, stimulate the emergence of local professional players and increase support for sand volleyball to become a tourism sport.
\end{abstract}

Keywords-dress code, Muslim female athlete, perception, religious values, sand volleyball

\section{INTRODUCTION}

Sand volleyball can be developed as one of the sport tourism attractions in Indonesia. [1], as Indonesia has many beautiful beaches where sand volleyball events can be organized as tourist attractions [2]. Moreover, sand volleyball is a well-known sport in Indonesia, especially in Nusa Tenggara Barat (NTB) Province. Even, volleyball athletes from this province have recorded some high achievements at national and international events [3]. Therefore, organizing sand volleyball championships at the national and international level can help attract many tourists, especially supporters who come to support their teams [4],[5].

However, organizing sand volleyball championship in Indonesia may deal with the dress code of female athletes, which is not in accordance with the cultural and religious norms of Indonesia. So far, sand volleyball is well-known as the sexiest sport in the world as the players, particularly female players, wearing a piece of bikinis [6], [7]. For this reason, it is important for sport decision makers in Indonesia to determine a more acceptable dress design for sand volleyball players, in order to stimulate the emergence of professional sand volleyball athletes from within the local communities and encourage sand volleyball as a sports tourism.

The type of uniform which contradicts Islamic religious and cultural values, such as the sand volleyball bikini, creates inner conflict for Muslim female athletes [8]. As the dress design affects the athlete's self-confidence [9], it is not uncommon for female Muslim athletes to quit from an event. This phenomenon is often seen when Muslim female athletes are required to wear a dress that is not in accordance with their religious norms [10], [11. In fact, the Olympic charter has emphasized a commitment to uphold the equal rights of everyone in sports, and every athlete is free from gender and religious discrimination [12]. Therefore, a dress code that discriminates against a community, such as sand volleyball female Muslim athletes, should not be maintained [8].

At first, the International Federation of Volleyball [13] stipulated a two-piece bikini as a formal dress for a female sand volleyball athlete in a competition. The dress model is adjusted to help players move quickly and flexibly on the sand [13]. However, the rule has received a lot of criticism and rejection since it was first implemented at the 1996 Atlanta Olympics. For example, [14] criticized the International Volleyball Federation (FIVB) for its dress policy that focuses too much on the athlete's body, but has no effect on the athlete's performance. Furthermore, the African Volleyball Federation, such as Morocco, Algeria, and Egypt urged the FIVB to consider a more covered outfit for a female sand volleyball athlete. The bikini dress for female athletes is against Islamic norms which are preventing Muslim female athletes from participating in sand volleyball events [15], [16], and is a form of discrimination against Muslim female athletes in sports [17], [18]. As a result, the rules for female sand volleyball athlete dress has been revised which, allows a female athlete to play with more covered clothes, even wearing a headscarf [19]

Nevertheless, female volleyball athletes choose particular dress and appearance to understand their identity [20], when they act as volleyball athletes and when acting as a part of a community and representing the identity of their community [21]. Psychologically, the female sand volleyball athletes have different preferences related to dress design when competing which, in turn, affects their attitudes towards the dress code [22]. For some athletes, the most important thing about an apparel design is to provide comfort 
and help improve performance. While other athletes want a fashionable clothing design, which can enhance the aesthetic value of their appearance. And for other athletes, they want clothes that do not attract the attention of many people and protect their femininity when playing volleyball [22], [23]. Therefore, this study aims to analyze the perceptions of Indonesian sand volleyball female Muslim athletes towards the formal dress of female sand volleyball in international events.

\section{METHODS}

This research adopts a qualitative approach in order to help the researcher understand the feelings and experiences of the research objects. The qualitative approach helps comprehend perception, behavior, motivation, and action of informants, as a whole and described in the form of words in a special natural context and by utilizing other natural methods [24]. This study aims to analyze and describe the perceptions, attitudes, and behavior of Muslim female athletes of sand volleyball in Indonesia regarding the female athlete dress code at international sand volleyball events. Purposive and snowball sampling approaches were used to recruit informants the female Muslim athletes, former athletes, and sand volleyball coaches.

Data was collected through online interview techniques, using WhatsApp, Zoom, and email. Such a mechanism was used as it was not possible to conduct direct interviews as a result of the Covid-19 pandemic. Interviews were conducted throughout August 2020. The data were saturated after 40 informants were involved. The 40 informants consisted of 28 sand volleyball athletes, former athletes, and sand volleyball athletes from the NTB area while 12 others came from outside NTB.

The status of one of the researchers as a senior national athlete facilitates the data collection process. Furthermore, the status makes it possible to adopt an auto-ethnographic approach where the experience of the researcher as an athlete was used as a reference in the current study. Data from the interviews were transcribed and analyzed using a content analysis approach. Content analysis helps identify the meaning of the words and thoughts of the informant [25].

In this approach, data is codified using certain words. Then, the words are grouped to form a concept based on their similarities and relationship. These concepts are linked and compared with one another in order to find a connection to identify the emerging themes. The themes that emerge are recorded and their frequency is counted, to be used in determining the level of consensus. The frequency with which themes emerge explains the overall issue within the data. The emergent themes are then grouped to form categories that answer the research problems.

\section{RESUlt AND DISCUSSION}

\section{The emergence of the three categories}

Thirteen themes emerged from the data. Each theme is analyzed and recorded based on its respective characteristics. The similar and related themes are grouped in order to form a category. The thirteen themes were then grouped into three categories: (1) authenticity and professionalism orientation; (2) compromise and achievement orientation; and (3) religious and cultural value orientation. A detailed discussion of each category is provided below.

\section{Category 1 Authenticity and professionalism orientation}

Category 1 was constructed by five emergent themes including the characteristics of sand volleyball, the culture of sand volleyball origin country, Comply with international rules, Comfort and flexibility, and Cohesiveness and professionalism.

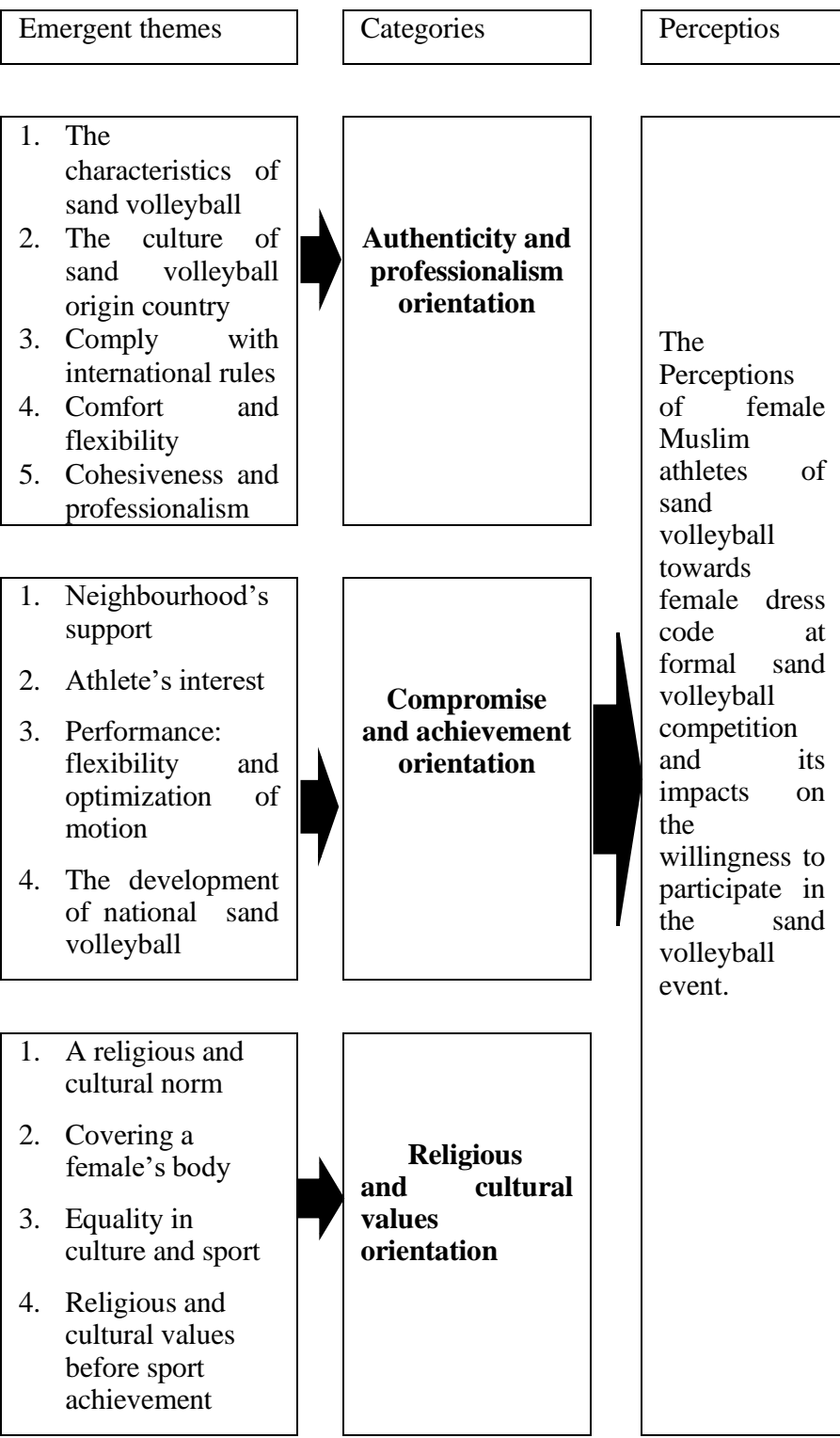

Figure 1. The emergent themes and categories of perceptions of female Muslim athletes towards the dress code at a formal sand volleyball competition

The characteristics of sand volleyball. Sand volleyball can be played as a part of recreational activities on the beaches and organized as a sports tourism event [26]. As an archipelago, Indonesia is rich with beautiful beaches which are suitable for sand volleyball events. This is evident in some regions where international sand volleyball sports events were organized, as commented by an informant: "In fact, because the beaches in Indonesia are good, Indonesia often hosts international competitions. That can be an 
opportunity for us to achieve, especially regional athletes can experience competition atmosphere, competing with athletes from outside" (AWM, 07). Thus, the beautiful beaches with natural surroundings should make Indonesia a mecca for sand volleyball activities, in order to stimulate the emergence of professional athletes.

Furthermore, sand volleyball can be established as a mainstay tourist attraction, as implied by an informant.

I think sand volleyball is an enjoyable sport, a sport that requires endurance, good skills, and good strategy. Sand volleyball also requires independence and responsibility, and teaches us to play as a team ... we must always trust each other with our partners. (AWM 04)

Such characteristics of sand volleyball, as implied in the above data, can provide social experiences to tourists when organized as sports tourism. The characteristics of sand volleyball are also identical with beach activities, as discussed below.

The culture of the country of origin of Sand Volleyball. Athletes have learned about sand volleyball culture which includes the people, language, fashion, and issues related to modern sand volleyball. Originating from Hawai and California, sand volleyball is associated with the beach lifestyle. An informant commented:

As far as I am concerned, sand volleyball was brought from abroad, not from a Muslim country..of course, the dress code adapts to the culture of that country. Moreover, this sport is performed on the beach, so it is adjusted to the beach activities ..., so it's no wonder if you wear a bikini". (AWM 03)

The above data implies that the sport dress is related to the culture and identity of a particular activity. A woman wearing bikinis when playing sand volleyball is promoting the culture of this sport, as added by an informant

I choose to wear a bikini when I compete. In my opinion, because of the country of origin, the culture of people that initiated the dress code must have been familiar with this, such dress must have been a common thing in that culture. As long as no overacting... whereas, in Indonesia we deal with Eastern culture, that is why some styles of clothing are considered too eccentric or a taboo matter. (AWM 04)

Thus, the prevalence of bikinis in women's volleyball is common so that some athletes never bothered with the uniform rules. Meanwhile, the ability of athletes to conform to the rules indicates the flexibility of the athletes' selfconcept through clothing [27], which portrays an attitude of professionalism. Thus, they play and respect the rules of dress issued by the International Federation of Volleyball (FIVB) as is the international rule of sand volleyball.

Comply with International Rules. Athletes generally describe the concept of a dress code as a rule to follow. There are different dress codes in a sport that are tailored to the needs of the sport, and the conditions where athletes will compete. An informant commented:

I personally have no problem... an athlete and each sport must have its own rules ... not only beach volleyball but maybe because beach volleyball is watched, the audiences are around us.... But there are also sports that wear sexy clothes like gymnastics, swimming.... like that. So I think it's fine, the rules are like that. Usually, they also dress like that only when they play in a formal competition, ...not every day (AWM, 12)

At the international level, the athletes have to adapt to the competitive atmosphere, including the uniforms they have to wear in each tournament. Some athletes, such as the informant, perceive the competition as a unique and special moment where there is a particular rule to follow. The athletes believe that such a rule of the game was made to help them enjoy the competition.

Comfort and Flexibility. Some athletes pointed out that a bikini is a comfortable uniform to wear when playing in the sand during hot weather. This is the evidence of how a sports dress is purposely designed to adapt to the environmental conditions and to meet the needs of the athletes, as expressed by an informant:

In my opinion, it's actually more comfortable when we play, because if we compete in a bikini and a burkini it is different mentally, but other than that the effects of other things if training and all kinds of things don't matter. ..... because we can move more freely and the sand doesn't stick in our clothes (AWM 35)

Indeed, for some female athletes, such as the above informant, wearing a bikini is a matter of focus to the competition, not to the audiences. By doing so, they feel that the bikini help make a comfortable and flexible movement, which in the end helps increase self-confidence to win the competition. Furthermore, some informants acknowledged that the dress code can influence the reputation of the athletes and their institutions, as discussed below.

Maintaining cohesiveness and professionalism. Some athletes associate the bikini dress when playing at a sand volleyball competition with the cohesiveness of a team, as noted by an informant: "Now I prefer to wear a bikini because it is more comfortable and because it suits my partner. ...during the competition everything must match what my partner's outfit". (AWM, 24). That is, wearing the same uniform shows cohesiveness in the game, which in turn increases the athletes' confidence during the competition.

Furthermore, the formal dress of sand volleyball is associated with professionalism, as expressed by an informant: "This sport is my profession so I am a professional, and I have to do the totality as I have decided. " (AWM 18). The athletes, such as the informant, acknowledge that to be a professional athlete requires devotion and sacrifice. They should focus not only to win the competition but also to make sand volleyball interesting and entertaining. One thing that can attract audiences and make the sand volleyball uniques is the distinctive clothing of its professional players. Above all, professional athletes are those who focus on performance and develop a solid team [28], regardless of the dress code.

Overall, the authenticity and professionalism orientation perceive the dress code of sand volleyball for female athletes as a rule that should be obliged and maintained. The dress characterizes beach and outdoor activities and maintains the culture of people where sand volleyball was first played. Furthermore, the dress helps create comfort and flexibility for players during competition and demonstrates the 
cohesiveness of a team and the professionalism of an athlete. However, other informants have different perceptions, as discussed below.

\section{Category 2. Compromise and Achievement Orientation}

This group perceives the importance of the development of sand volleyball in Indonesia both as a sport and as a tourist attraction. Therefore, the implementation of a dress code for female Muslim sand volleyball players should consider the support from the athletes' environment, athlete's interest, and athlete's performance, and the development of national sand volleyball.

Environmental Support. Some of the informants stated that choosing to wear bikinis in the sand volleyball competition depends on the support the athletes receive from their family and neighborhood, as stated by an informant:

I prefer following the rules...because it's just like a common thing, so like my big family has no one complains whatever I decide to wear in the competition... Unless if I walk around wearing bikinis, they may expel me from home ... but because this is a professional in the competition...so be it (AWM 06)

The family support provides comfort and assurance for athletes, including wearing formal sand volleyball clothes in a tournament. However, not all female Muslim athletes wearing bikinis were supported by their families, as expressed by an informant: "Now it is more comfortable with a more covered dress ...before, my family was uncomfortable seeing me wearing bikinis, but thank God, here now I get more support. "(AWM 05). In fact, support from the family affects the decisions and mental competitiveness of athletes. Lack of support will put them in difficult choices, which in turn affect the athletes' decision to be professional sand volleyball athletes. Thus, the flexibility of these rules is expected in order to increase the interest of many female Muslim athletes to participate, as discussed below.

Interests of Athletes. Several informants stated that the dress code influenced their decision to become sand volleyball athletes at the beginning of their careers. One of the informants commented: "In the past, there were very few who wanted to participate because not only we had to play in hot weather, but also we had to wear bikinis... it made us here in the small town unwilling to participate" (AWM 38). Changing the dress code into a more flexible choice has increased Muslim women's interest in sand volleyball and becoming professionals, one informant said:

Previously, I wanted to enter a sand volleyball club, but I was still hesitant about joining the club because of the athlete's clothes. The rules used to be very strict....the female athletes had to wear bikinis in a formal event, but now the clothes are allowed, so now I am sure and want to focus on sand volleyball. At first, wearing the hijab in a competition was hot, but now I feel comfortable and still chose to wear the hijab. (AWM 29)

However, despite the flexibility of the dress code, some athletes voluntarily wear bikinis when competing. This means that the flexibility of the rules gives athletes the freedom to determine the type of clothing they want and focus on their sports achievements, as told by an informant:
It's like having a doubt, half-heartedly when wearing a bikini for the first time... I felt uncomfortable but gradually get used to it as it is a process.... There are times when you are embarrassed because the culture where sand volleyball comes from is already like that, even though we, Indonesian, have a different culture, but again it's my profession, so it's a job I choose and a hobby that I like. (AWM 01)

In this case, the athlete's interest determines their choices. Importantly, the flexibility in the dress code for sand volleyball events can stimulate the interest of female Muslim athletes to participate in the competition. The athlete's performance takes precedence over the dress issues, as discussed below.

Athlete Performance. Performance in this section is defined by the informants as mental strength to compete and freedom of movement so that the athletes are able to control and win the match. As a result, the dress issues were not perceived as a problem by some informants. The athletes do not focus on the dress issues, instead, they focus on how to follow the match with the best performance and win the match, as stated by an informant: "...I should be professional and focus on the competition...we come to compete and supported by state money, so everyone gives his best" (AWM 33). For a Muslim female athlete, particularly Indonesian athletes, wearing minimized clothing such as a bikini is a taboo, both culturally and religiously. However, according to this group of informants, the athletes must remain professional and give good performance. That may be a way to support the development of sand volleyball in Indonesia.

The development of national sand volleyball. The informants in this group perceived that the focus should be given to the development of sand volleyball in Indonesia, not to the dress code, as expressed by an informant:

In the past, only a few provinces in Indonesia developed sand volleyball, and even then, not all female athletes are purely sand volleyball athletes, but most of the athletes are from indoor volleyball. Especially in NTB, we can still count on our fingers if we want to know the athlete. (AWM 38)

This data implies the slow development of sand volleyball because not many female Muslim athletes are attracted due to the dress code for competition. The informants noted that the dress code should not be an obstacle to the development of sand volleyball in Indonesia. Indeed, according to this group of informants, some sacrifices in terms of values may be required from the athletes' site, meanwhile, at the same time, the rule should respect local norms where the event takes place.

Overall, the category of compromise and achievement orientation perceives that the dress code should support the comfort of athletes and help build self-confidence in attempting achievement. In this case, the dress code must be adjusted in order to gain support from the athlete's environment on the one hand and provide independence of the athletes on the other. Professional athletes will not bother with clothing design but will focus more on performance and achievement. These perceptions differ from those described in the third category below.

Category 3. Orientation of Religious and Cultural Values 
Informants in this group perceive that the sand volleyball dress code should not conflict with the religious and cultural values of the local community, in this case, in Indonesia. Such perceptions are expressed in four emergent themes including religious and cultural norms, covering women's bodies, religious and cultural identities above sports achievements, and equality in culture and sport.

Religious and Cultural Norms. According to some informants, the rules of the sand volleyball competition should remain the same everywhere, but the athletes' dress is adjusted to local norms. An informant commented:

As far as I am concerned, sand volleyball was introduced in non-Islamic countries. Of course, the dress code adapts to the culture of that country. However, in my opinion, this does not mean that modifications cannot be made...we need to adopt the dress of local culture the competition takes place without reducing/limiting the freedom of movement of the players. (AWM 39)

The athletes, such as the informant, perceived that the rules should take into account the needs of a minority population of athletes who come from within Muslim communities. Indeed, the dress issue is sensitive to many Muslim female athletes, as stated by an informant: "Before, I wanted to join a sand volleyball club.....move from indoor volleyball, but I was still hesitant with the dress code, I have to change my hijab with a bikini,...this is something that I cannot do "(AWM 04). As a result, there should be flexibility in the dress code in order to respect the athlete's religious values, as noted by one informant:

The dress code should also adapt to the culture and norms prevailing in each environment. In any sport, Muslim women should still be able to maintain their integrity and belief, and the dress code in any sport should not violate norms and ethics (AWM 06)

The above data imply that the flexible dress code which is accepted by local norms can help female Muslim athletes perform. The female Muslim athletes will feel more comfortable and focus on competing as their clothes are designed in accordance with their values, as discussed below.

Covering women's bodies. According to the informants, the common Islamic teaching strongly encourages adult women to cover the whole part of their body except their face and hands. For some female athletes of sand volleyball, the way to dress reflect their devotion to the religious teachings. Dressing according to Islamic law is the practice of morals towards oneself, and respecting one's own dignity as a noble being. An informant stated: "As a Muslim, we dress like that not because of our obligation..., but it is a form of our submission to Allah, the Almighty God, especially, it is a part of worship." (AWM 17). In fact, the religious belief is someone's identity, as noted by an informant:

As a Muslim, I have to dress Islamically, while exercising I also keep wearing the hijab.. I still want to be a Muslim woman and an athlete who obeys religious rules. Nowadays, there is no problem wearing a hijab when playing volleyball, as long as we are comfortable it won't interfere with the activities..."(AWM 30)
Interestingly, some athletes, such as the informant, perceived sport as a way to introduce their identity and to feel equal in terms of beliefs and personalities with others.

Furthermore, some informants associate the athlete dress with fashion which is adaptable to innovation, as revealed by an informant:

I think it is more appropriate to wear Islamic clothes. As my answer before, the fashion world continues to innovate in adapting its style to the needs of consumers, including female volleyball athletes. There is no reason not to wear my Islamic dress which more secure for me ... including for female sand volleyball athletes because it is an obligation in Islam. "(AWM 28)

In such an Islamic fashion model, a Muslim female athlete may wear the headscarf in competitions, in keeping with their commitment to religious obedience and the practice of modesty. The dress will protect the athletes' bodies from exposure and consumption of audiences. The dress will help audiences focus on the athletes' performance and not on their bodies. Furthermore, sports should touch all groups in the society including female Muslim athletes who adhere to their religious teachings as further discussed.

Religious and Cultural Identity Above Sports Achievement. Some of the informants explained that dress is related to a job identity in addition to personal identity. Work should not contradict personal principles, as reflected in the statement of an informant: "How many athletes have been summoned by the national sports committee but, then resigned as they were informed to wear a bikini in the competition. So, they prefer not to join the competition rather than putting off their hijab" (AWM 02). This data reflects athletes' commitment to their self-identity which takes precedence over job identity and professionalism. Such a phenomenon can affect the recruitment process of sand volleyball athletes in Indonesia, which in turn, affects the whole sport achievement of Indonesia in the world.

Some Muslim female athletes have a strong understanding and commitment to their religion. For them, practicing religious teachings is a matter of pride and selfrespect, as expressed by an informant:

Oh no, when I decided to wear a hijab while competing, I also used a long slave so I didn't wear a bikini anymore after the last ASEAN games at that time. I decided that wearing the hijab meant that I competed with the hijab because of my Muslim identity. If I am not allowed to compete in this Islamic dress, I better resign from my career as an athlete (AWM 01)

In other words, for some athletes, religious and cultural teachings are more important than sports achievement. Thus, for this group, success is related to obtaining a social identity as an athlete on the one hand and practicing religious and cultural teachings as self-identity on the other hand. This is an interesting phenomenon that should be taken into account when establishing equality of culture in the sports world, as further discussed below.

Equality in culture and sport. Informants acknowledged that the International Federation de Volleyball (FIVB) updated its dress code in 2012 to allow players to wear shorts and sleeved tops in an effort to be more inclusive and respect 
the different beliefs and cultures in the world. FIVB allows female athletes to compete wearing trousers and long $\mathrm{T}$ shirts, as well as a head covering, according to their respective beliefs. This flexibility in dress code, especially for Muslim female athletes, increases the motivation to participate and play sand volleyball, as stated by an informant:

This is great for all Muslim women, so they won't be afraid to join this sand volleyball club. Previously, there were many who didn't want to join because we had to play in the heat and rain and wear those small bikinis..., that is not our culture. So now with this burkini, we like it and, yes, more people are getting into this beach volleyball sport (AWM 36)

In some countries with a majority Muslim population such as Indonesia, the change in the dress regulations is good news. An informant added: "In the past, I wore a bikini because I had to be a professional, but since there were no rules against it, I chose to wear more covered clothes so I no longer have to worry about my belief in the sport" (AWM 22). This is, indeed, a great consensus in which, Muslim female athletes can still participate in sand volleyball without being hesitant with their beliefs.

Overall, the informants in the third group perceived that the dress code of female sand volleyball athletes should not conflict with the nature of athletes as a woman following their religious and cultural values. The female athletes behave, including dress, following the religious and cultural norms they adhere to. In the context of Indonesia, dressing aims to cover the body which reflects the personal identity, and acquire acknowledgment from others as a member of a particular community. Apart from the authentic dress of sand volleyball players, athlete's dress should be adaptable to local culture and norms. Indeed, sports and clothing issues are inseparable two entities. Therefore, sports, particularly sand volleyball, should provide and maintain equality for all nations in terms of culture and norms.

After the text edit has been completed, the paper is ready for the template. Duplicate the template file by using the Save As command, and use the naming convention prescribed by your conference for the name of your paper. In this newly created file, highlight all of the contents and import your prepared text file. You are now ready to style your paper; use the scroll down window on the left of the MS Word Formatting toolbar.

The purpose of this study was to analyze the perceptions of female Muslim athletes towards the dress code for female athletes at the sand volleyball event. The study found three categories of perceptions as discussed below.

Autenticity and Profesionalism Orientation. Athletes who are oriented towards authenticity and professionalism argue that sand volleyball is a sport that has its own characteristics that distinguish it from other sports. Clothing is a characteristic that distinguishes a person from other people [29], [30], in this case, the dress of a female sand volleyball athlete distinguishes it from other sports athletes. The athlete's dress in sand volleyball context, not only makes the sand volleyball interesting and unique, but the dress designs help athletes perform various movements flexibly, which in turn improves their performance during competition [22].
In addition, the design of women's sand volleyball athlete dress represents the characteristics of gender [21]. The dress design adopts the type of women's clothing for beach and outdoor activities in summer in the country where the sand volleyball sport was created. Therefore, a professional sand volleyball athlete should follow the established dress code to maintain the authenticity of the sport's characteristics [27]. Furthermore, one of the characteristics of professional sand volleyball athletes is focusing on developing self-potential in sports, and differentiating the sports atmosphere from other social situations [28], so that the designs of formal sand volleyball dress for females should be maintained.

Compromise and achievement orientation. Athletes who are oriented towards compromise and achievement tend to expect the dress code to be tolerated, and to give female athletes the freedom to choose. This opinion is based on the argument that sport is an activity that has its own rules, and should be distinguished from the athlete's dress code. The design of athletic clothing does not affect the perfection of a game and sporting event. However, dress design affects athletic comfort [23] and athletes' mental of competitiveness [31], [32]. Therefore, female Muslim sand volleyball athletes should gain the privilege to choose their dress designs that gains support from their respective environments and makes them comfortable [33], which reflects their characteristics [20], so that they play with a high level of self-confidence [23] to create optimum achievement [9].

This compromise and achievement-oriented perception suggest that the flexibility in the athlete's dress code can increase the participation of female Muslim athletes in the sand volleyball competition [10]. Furthermore, certain dress designs are no longer a problem for some athletes when they become champions and professional players. At this level, motivation and self-image issues to become a professional sand volleyball athlete and be the best player are more important than the dress code issues [32]. Therefore, the dress code should be contextualized with the sociological (such as support from family and wider social environment) and psychological (self-confidence) issues of the athletes in order to increase participation and to stimulate the emergence of professional athletes.

Religious and cultural values orientation. The athletes who are oriented towards religious and cultural values contend that the current dress code of female athletes at the sand volleyball event is not in accordance with the Islamic religious values. The dress design covers only a small part of the athlete's body so that the religious female Muslim athletes cannot participate in a formal sand volleyball match [34], [35]. Such dress code issue frequently affects a number of Muslim women participating in a formal sand volleyball competition [36], [37], which in the end, reduces the opportunity to make sand volleyball one of the tourist attractions in Indonesia, particularly in the NTB Province.

The current dress design of sand volleyball female athletes is not adaptable to the social and cultural norms of Islamic societies [38]. Meanwhile, the clothing styles and appearances are the reflections of a person's identity and characteristics [20]. For many communities, dress design represents the community's characteristics. Therefore, the female athletes who come from such communities and wearing bikinis in a volleyball tournament may be 
considered disrespectful to their identity and given social punishment from their families and communities [11].

According to Religious and cultural values orientation, sport is a part of religious teachings, because it is related to maintaining physical and spiritual health. Therefore, all provisions in sports should not contradict the religious and cultural norms of local communities [34]. In this case, the identity and characteristics of local society should be adopted and allowed to develop in sports activities as a form of respect for equality in culture. Every female athlete has the same opportunity to be a champion and professional athlete without being hindered by dress code issues. The findings of this study have a theoretical and managerial impact as shown below.

\section{Theoretical implications}

This study found three groups of perceptions of female Muslim sand volleyball athletes in Indonesia regarding the dress code of female athletes at a formal sand volleyball competition which make several theoretical implications. First, the findings extend our understanding of [22]'s contention regarding female athletes' preferences for dress design in a competition. The Authenticity and Professionalism Orientation elaborate athlete's preference in [22]'s contention for a dress that provides flexibility, help increase performance, fashionable, and attractiveness of the game. Meanwhile, the Compromise and achievement orientation and Religious and cultural values orientation explain the athlete's preference to focus on the competition and sport achievement while protecting their body from exposure and social problems.

Second, the perceptions of athletes who are oriented towards sports authenticity and professionalism tend to support the dress code of international sand volleyball events and choose to follow the rules. They perceive bikinis as identical with sand volleyball characteristics and relates the dress with an attitude of professionalism and the identity of professional sand volleyball athletes. The finding reinforces the results of previous research by [21] regarding the ability of a female athlete to distinguish her identity by their daily clothing appearance: when she becomes an athlete, a feminine woman, and a member of a community.

Third, Compromise and achievement orientation elaborate the athletes' perception regarding the flexibility in the dress design for a competition, in order to help create the athletes' comfort and confidence. These findings elaborate the results of previous research by [31] and [32] regarding the need in contextualizing the rules of the sport with local norms so that the athletes can gain support from their environment. Further, the findings bring managerial implications.

\section{Managerial implications}

The results of this study recommend several managerial implications for the government, the Indonesian and international sand volleyball federation, and the tourism industry. To follow up the change in the FIVB regulation regarding the dress code for female athletes of sand volleyball, the government together with the Federation for sand volleyball in Indonesia (PBVSI) can issue a dress code policy for local sand volleyball events which is in accordance with the Indonesian culture. The government and the PBVSI can also encourage the establishment of sand volleyball networking with countries that have similar socio-cultural characteristics to Indonesia, such as Malaysia, Brunei Darussalam, and other countries.

To develop the tourism sector, the government together with PBVSI and tourism industry players can organize regular inter-regional (provincial) sand volleyball competitions as a forerunner to the emergence of competition events between countries, which are held in tourist destinations. The dress code of the players can be adjusted to the religious and cultural norms where the event takes place.

Finally, the government can provide incentives to female sand volleyball athletes, especially Muslim female athletes. Athletes who have perceptions like those in category 1 can be encouraged to become professional athletes of sand volleyball at the international level. Meanwhile, athletes whose perceptions fall into categories 2 and 3 can be encouraged to participate in the establishment of sand volleyball as a tourism sport in Indonesia. In such sport, the rule for the events can be unique following the local characteristics.

\section{Limitations and future direction}

This research involves small samples of female Muslim athletes of sand volleyball in Indonesia, which may not be truly indicative of all Muslim athletes and people in Indonesia. Despite the careful selection of the informants, they may not represent the complete picture.

This study found differences in the perceptions of sand volleyball athletes towards dress code, indicating differences in the values and expectations of the athletes and the supporters. Such differences may reflect the condition of people's perspectives towards sand volleyball events. Thus, it is interesting to further research people's perceptions of the sand volleyball event to ensure the level of their participation in making sand volleyball a sports tourism attraction, particularly in the context of Indonesia and the NTB Province.

\section{CONCLUSION}

The Muslim female sand volleyball athletes have different perceptions regarding the dress code for female sand volleyball athletes at a formal competition. The different perceptions were influenced by the different expectations toward the future career in volleyball sport and the Islamic personal values. The athletes who expected to become professional players perceived the dress code as a typical dress design to help increase players' performance and represent the volleyball's unique characteristic. However, the athletes who have strong Islamic values perceived the dress code as an inhibitor to their participation in the sport. Further, the study results create theoretical and managerial implications.

\section{ACKNOWLEDGMENT}

We thank The Ministry of Research and Technology / The National Research and Innovation Body that has funded the research for a student thesis, which leads to the submission of this journal. 


\section{REFERENCES}

[1] A. W. Utomo, Perkembangan Industri Olahraga Obyek Wisata dan Rekreasi di Kabupaten Magetan. In Prosiding Seminar Nasional Ilmu Keolahragaan UNIPMA, 1 (1), 2018. Pp. 116-126.

[2] I. A. Wong and S. L. W. Tang, "Linking travel motivation and loyalty in sporting events: The mediating roles of event involvement and experience, and the moderating role of spectator type,"Journal of Travel \& Tourism Marketing, 33(1), pp. 63-84, 2016.

[3] M.R. Lubis, B. Satrianingsih and J. Irmansyah, "Evaluasi program pembinaan prestasi cabang olahraga bola voli pantan di NTB," JIME 3 (2), $223-231,2017$.

[4] A. Razak and R. Suprihardjo, "Pengembangan Kawasan Pariwisata Terpadu di Kepulauan Seribu," Jurnal Teknik ITS, 2(1), pp. C14-C19, 2013.

[5] D. Widiyanto, J. P. Handoyo and A. Fajarwati, "Pengembangan pariwisata perdesaan (suatu usulan strategi bagi desa wisata Ketingan)," Jurnal Program Studi Pembangunan Wilayah Fakultas Geografi UGM. Yogyakarta, 2008.

[6] K. L. Bissell and A. M. Duke, "Bump, set, spike: An analysis of commentary and camera angles of women's beach volleyball during the 2004 summer Olympics," Journal of Promotion Management, 13(1-2), pp. 35-53, 2007.

[7] J. A. Corlett, “Are women beach volleyballers 'Too sexy for their shorts?," Symposion, 4(1), 7-15, pp. 2017.

[8] K. J. Erickson, “Understanding Minnesota Muslim Girls' Experiences with Current Sports Uniforms and Their Preferences for the Design of Culturally Sensitive Sports Uniforms," M.Sc. thesis, The Faculty of The University of Minnesota, 2017

[9] C. Yuksel, J. M. Kaldor, D. L. James and S. Marschner, "Stitch meshes for modeling knitted clothing with yarn-level detail," $A C M$ Transactions on Graphics (TOG), 31(4), pp. 1-12, 2012.

[10] M. K. Marwat, Z. U. Syed, W. Muhammad, K. Hazratullah and B. Safeena, "Sport performance of Muslim women and different constraints in their way to participation in sport". International Journal of Humanities and Social Science, 4(10 (1)), pp. 208-214, 2014.

[11] Y. I. Qureshi and S. A. Ghouri, "Muslim female athletes in sports and dress code: Major obstacle in international competitions," Journal of Experimental Sciences, 2 (11), pp. 9-13, 2011.

[12] T. Benn and S. Dagkas, "The Olympic Movement and Islamic culture: conflict or compromise for Muslim women?," International Journal of Sport Policy and Politics, 5(2), pp. 281-294, 2013.

[13] FIVB, "Official beach volleyball rules," Federation International de Volleyball, pp. 1-72, 2016 [online]. Available: https://www.fivb.org/EN/Refereeing-Rules/Documents/FIVBBeachVolleyball Rules 2017-2020-EN-v05.pdf. [ Accessed August 12, 2020].

[14] P. R. Sailor, S. Teetzel and C. Weaving, "No Net Gain: A Critique of Media Representations of Women's Olympic Beach Volleyball," Feminist Media Studies, iFirst, pp. 1-5, 2012. [Online]. Available: https://www.researchgate.net/publication/241721994 No Net Gain A_critique_of_media_representations_of_women\%27s_Olympic_bea ch volleyball. [Accessed Aug. 12, 2020].

[15] N. Cortis, P. Sawrikar and K. Muir Participation in sport and recreation by culturally and linguistically diverse women. Sydney, Australia: Social Policy Research Centre, University of New South Wales, 2007.

[16] C. Weaving, "Buns of Gold, Silver, and Bronze," in The Olympics and philosophy. Ketucky: University Press of Kentucky, 2012, pp. 228-241.

[17] M. Turkmen, "Religiosity and female participation in sport: exploring the perceptions of the Turkish university students," Physical education of students., Vol 22 no 4 pp 196 - 206, 2018.

[18] M. R.Wirdati Muslim Women and Sports in the Malay World: The Crossroads of Modernity and Faith. Chiang Mai: Silkworm books, 2006
[19] BBC NEWS, "Jilbab di pertandingan bola voli pantai?," BBC NEWS Indonesia, 10 Aug, 2016. [Online]. Available: Factiva, https://www.bbc.com/indonesia/dunia/2016/08/160809_olahraga_oli mpiade_hijab. [Accsessed Dec. 16, 2020].

[20] M. Kang, M. Sklar and K. K. Johnson, "Men at work: using dress to communicate identities," Journal of Fashion Marketing and Management., vol. 15 no. 4, pp. 412-427, June 2011.

[21] J. A. Pattison, "Female collegiate volleyball athletes' perceptions of identity, specific to sport and gender, as understood by their in-sport and everyday dress and appearance practices," Ph.D dissertation, Lousiana State University and Agricultural and Mechanical College, 2013.

[22] F. Skillen, "Woman and the Sport Fetish': Modernity, Consumerism and Sports Participation in Inter-War Britain,"The International Journal of the History of Sport, 29(5), pp.750-765, 2012.

[23] K. Kato, S. Jevas and D. Culpepper . Body image disturbances in NCAA Division I and III female athletes. The Sport Journal, 14(1). P. 2, 2011.

[24] L. J. Moleong, Metodologi Penelitian Kualitatif, cetakan XXIX. Bandung: PT. Remaja, Rosdakarya, 2011.

[25] S. Sarantakos. Social research 3rd ed. New York: Palgrave Macmillan, 2005.

[26] E. Rivani. Potensi Asian Games 2018 Bagi Perekonomian Indonesia, Info Singkat Bidang Ekonomi dan Kebijakan Publik, Kajian Singkat Terhadap Isu Aktual dan Strategis. Pusat Penelitian Badan Keahlian DPR RI X(10)/II: pp. 19-24, 2018.

[27] B. Hannover and U. Kühnen, "The Clothing Makes the Self" Via Knowledge Activation 1. Journal of Applied Social Psychology, 32(12), pp. 2513-2525, 2002.

[28] D. Connaughton, R. Wadey, S. Hanton and G. Jones, "The Development and Maintenance of Mental Toughness: Perceptions of Elite Performers", Journal of Sports Sciences, 26(1), pp. 83-95, 2008.

[29] M. Solomon and N. J. Rabolt. Consumer behavior in fashion. Englewood Cliffs, NJ: Prentice Hall, 2004

[30] M. S. Sontag and J. Lee, "Proximity of clothing to self scale," Clothing and Textiles Research Journal, 22(4), pp. 161-177, 2004.

[31] E. M. Cross, "The Uniform Effect: Collegiate Student-Athletes' Experiences with Competition Athletic Apparel and Self Perception," Ph.D dissertation, Virginia Tech, 2011

[32] J. A. Steinfeldt, R. A. Zakrajsek, K. J. Bodey, K. G. Middendorf and S. B. Martin, "Role of uniforms in the body image of female college volleyball players," The Counseling Psychologist, 41(5), pp. 791-819, 2013.

[33] K. Toffoletti and C. Palmer, "New approaches for studies of Muslim women and sport," International Review for the Sociology of Sport, 52(2), pp. 146-163, 2017.

[34] T. Kay, "Daughters of Islam: Family influences on Muslim young women's participation in sport," International Review for the Sociology of Sport, 41(3-4), pp. 357-373, 2006

[35] J. A. Wilson and J. Liu, "The challenges of Islamic branding: navigating emotions and halal," Journal of Islamic marketing, Vol 2(1), pp. 2011.

[36] N. Ahmad, "Toward advancing debates on Islamic marketing: a renewed perspective" Journal of IslamicMarketing, Vol. 9 No. 1, pp. 152-166, 2018.

[37] M. Hamzeh, "FIFA's double hijabophobia: A colonialist and Islamist alliance racializing Muslim women soccer players," Women's Studies International Forum, Vol. 63, pp. 11-16, July 2017.

[38] M. Hamzeh and K. Oliver, "Because I am Muslim I cannot wear a swimsuit', Muslim girls negotiate participation opportunities for physical activity," Research Quarterly for Exercise and Sport, Vol.83 No.2. pp. 330-339, 2012. 